DOI: 10.2478/eurodl-2014-0027

\title{
THE FLIPPED-CLASSROOM APPROACH: THE ANSWER TO FUTURE LEARNING?
}

\author{
Gila Kurt:[kurtzgila@gmail.com], AlexandrTsimerman, Orna Steiner-Lavi, \\ The College for Academic Studies, 46 Ben Gurion St., Ramat Hasharon, Israel
}

\begin{abstract}
The study examines students' assessments of the use of the flipped classroom approach in an undergraduate course in the Business Department at the College for Academic Studies in Israel. In its essence, learners prepare for classes by watching videos away from class, allowing the classroom encounter to focus on discussion, exercises, and discourse. Data were collected by a questionnaire distributed toward the end of the course. The students reported that watching videos between lessons enhanced interest, alleviated boredom, and enriched the learning. To a lesser extent, they reported it increased their involvement in learning, understanding of the learning material, and confidence in their ability to understand it. While acknowledging the convenience of watching course videos between classes, however, the participants clearly preferred to watch them in class. Multivariate analysis revealed that working students were less positive about using the flipped-classroom approach than non-working students, female students were more positive than male ones, and older students were more positive than younger ones. Furthermore, the stronger the senses of having classmates nearby, the more positive the participants were about the contribution of watching the videos.
\end{abstract}

Keywords: Flipped-classroom approach, Higher education, Improving classroom learning, Educational videos

\section{Introduction}

The flipped-classroom model is a pedagogical approach that has become something of a buzzword in the last recent years. In its essence, learners prepare for classes by watching videos away from class, allowing the classroom encounter to focus on discussion, exercises, and discourse on the basis of what students learned from the videos. The origin of the flippedclassroom approach is attributed to a number of researchers and teachers. For example, the researcher Baker wrote about Classroom Flipping in a paper from 2000 described the evolution of the classroom teacher from "the sage on the stage" to "the guide on the side" (Baker, 2000). Also, the science teachers Bergmann and Sams started employing the flipped classroom model in 2007 (Noonoo, 2012). Later, Salman Khan, who in March 2011, on Ted Talk, introduced his initiative for the development of short videos in mathematics. The idea was that students should watch the videos before class, freeing the teacher to focus classroom time on discussion, exercises, and helping those who have difficulty. At the present writing (August 2014), more than 2,600 clips have been produced on a range of topics in mathematics, biology, and physics, to name only a few (https://www.khanacademy.org). Allowing students to watch videos before class, at the time of their choosing, as often as they wish, and stopping wherever they feel necessary, is revolutionary - a "flipping" of the traditional model of classroom learning. In this 
new paradigm, the "lecture" is studied online and away from class and the "homework" is done in class itself.

Studying course content before a lesson in class is not a novel idea in education. According to the traditional teaching model, students were and are still required to read materials in preparation for class meetings. However, now that the online infrastructure and advanced technological applications have been maturing, the dissemination of the flipped-classroom idea, based on videos as learning media, has been advancing with greater celerity.

Studies show that videos have a major advantage over static photos because they provide more information and can facilitate a deeper understanding of the contents presented (Al-Seghayer, 2001; Lewalter, 2003; Fletcher \& Tobias, 2005; Mayer, 2005; Jukes, McCain \& Crockett, 2010) Furthermore, meta-analysis of studies on the integration of visual representations into learning reveals that, even though there is no direct correlation between the use of videos in the learning process and learners' achievements, the memory retains learning material longer in video form than in static content (Means et al., 2010).

By adding learning time outside the physical classroom, the flipped-classroom model offers the possibility of expanding the learning process and intensifying students' interaction with the scholastic material (Anderson, 2010; Moore \& Kearsley, 2005). Furthermore, the transfer of responsibility for online study to a location away from the classroom promotes a sense of control of the learning process and flexibility in carrying it out, both of which potentially enhancing the student's involvement and motivation (Moore \& Kearsley, 2005; Palloff \& Pratt, 2011; Subrahmanyam \& Šmahel, 2011; Brookfield, 2013; Morse, 2013; Bonk \& Kahoo, 2014; Li et al., 2014; Piersol, 2014; Selwyn, 2014).

Despite this salutary potential, possible negative implications of self-directed online study, away from the classroom, should not be overlooked. In the absence of a facilitating teacher who provides feedback, students may misunderstand the contents and feel burdened when studying them. The lack of direct interaction with teacher and classmates, the sense of being alone, and the loss of self-confidence in study may impair the personal learning process, subvert scholastic selfesteem, and cause frustration (Lee \& Chan, 2001; Lim, 2002; Zhan \& Mei, 2013). One variable that attenuates these adverse effects is social presence, by which it is meant that learners who strongly value the proximity of instructor and peers find this helpful to them in the learning process. In particular, it helps them to perform online, away-from-class activities (Lomicka \& Lord, 2007).

The paucity of empirical research on the implications of using the flipped-classroom approach in the educational learning process is what prompted us to conduct this study. The goal of the study is to assess the attitudes of students who piloted the use of this approach in an undergraduate course toward the learning process and the contribution of the flipped-classroom to this process. It is hoped that this study will allow a deeper understanding of the implications of using the flipped-classroom approach among students and help teachers who wish to add this approach to their educational toolkit.

\section{Purpose of the current study}

The main purpose of this study is to examine students' attitudes toward the implementation of the flipped-classroom approach by soliciting their evaluation of (a) watching videos between classes and its contribution to the learning process, and (b) the convenience of watching videos between classes. We also investigated the relations between the students' evaluation of the contribution of the flipped-classroom approach, with their background characteristics and feelings about the course and their self-assessment of their learning ability. 
The following research questions are derived from these elements:

1. How do students assess the contribution of the flipped-classroom approach to the learning process and the watching of videos between classes as against the watching of videos in class?

2. What are the relations between the assessment of the contribution of the flippedclassroom approach to the learning process and the students' background characteristics, feelings about having the lecturer and classmates nearby, and self-assessment of the learning ability?

\section{Research method}

\section{Course and participants}

This study took place among undergraduate students from the Business Department at the College for Academic Studies in Israel who were taking an elective course in their advanced studies called "The Advertising and Media World in the 21st Century". Forty-five students were enrolled. The course, taught in weekly face-to-face classes over a thirteen-week period, concerns itself with theory and performance of advertising and media and recent changes in the field. It exposed students to the academic fundamentals and possible practical uses of advertising activity. Students also learnt to assess the effects of advertising on consumer attitudes and study the development of advertising strategy in all respects. In addition, they analyzed an advertising campaign for a product of their choice and produced advertisements for diverse products.

The flipped-classroom approach was applied in the following way: before each class meeting, the students were asked to watch a video lecture with a scholastic topic that would be discussed in class. During the face-to-face meetings students were given the opportunity to link their online video viewing with course materials presented in class by discussing events brought out from the field by the lecturer and/or classmates. For this purpose, ten videos were developed by a commercial firm in conjunction with a team from the College on the basis of the ADDIE (Analyze, Design, Develop, Implement, Evaluate) learning design model. Each video lecture was accompanied by an avatar of the course lecturer, using his real voice, and audiovisual representations of contents. Each video was ten minutes long at the most, and the ten videos were uploaded to YouTube for viewing. These video lectures are considered as a picture-in-picture learning video type that displays an instructor's image, instructor's voice, lecture slides and multiple multimedia elements. This technique combines a close-up of the instructor, which is overplayed to the slides and/or animations and has a high degree of media richness that ultimately can improve learning performance (Chen \& Wu, 2015).

Altogether, forty-one students responded to the questionnaire ( $91 \%$ response rate). Most respondents were women (80\%). The respondents' average age was $24(\mathrm{SD}=1.7)$ and the majority were employed-part-time $(50 \%)$ or full-time $(33 \%)$. The non-employed were a minority $(17 \%)$.

\section{Measures}

The research data were gathered by means of a questionnaire composed of twenty multiplechoice items that solicited students' evaluation of the use of the flipped-classroom approach in the course, self-assessment of their learning abilities, and their sense of closeness to the course lecturer and classmates. In an open-ended item, the students were asked to describe in detail their experience of watching of the videos between class meetings. A draft version of the questionnaire was sent to several participants as a pilot for feedback; their remarks and suggestions were helpful in developing the questionnaire in its final version. 
The questionnaire was divided into the following topics:

1. Introduction-explaining the purpose of the questionnaire, estimating the amount of time needed to fill it in, and assuring the confidentiality of the findings.

2. Attitudes toward use of the flipped-classroom approach in the course-these items were patterned after items from Meishar-Tal, Kurtz, and Pitterse (2012) and Kurtz (2013; 2014), which investigated students' attitudes toward the use of digital communication technologies in academic courses, adapted to the current study.

3. Sense of having the course lecturer and classmates nearby - these items were based on statements from the Teacher Student Relationship Inventory (TSRI) (Ang, 2005). In its original form, the questionnaire asked teachers to report attitudes toward students. In the current study, an adjustment was made for students to report about the course lecturer and classmates: "If I have a problem in learning the course, I am likely to ask the lecturer for help"; "If I have a problem in learning the course, I am likely to ask my classmates for help".

4. Assessment of learning ability—based on statements from Heatherton and Polivy (1991), State Self-Esteem (SSES): "I feel that I have less scholastic ability right now than others"; "I feel that I am having trouble understanding things that I read"; "I feel frustrated or rattled about my performance" (Cronbach's alpha $=.674$ ).

5. Personal background characteristics and assessment of the course-age, gender, and employment.

\section{Data collection and statistical processing}

The students filled in a hard-copy questionnaire during their last class meeting, on May 18, 2014. The response data were keyed into SPSS-21 for statistical processing.

\section{Findings}

\section{Research Question 1-How did students assess the contribution of the flipped- classroom approach to the learning process and to the watching of videos between classes, as against the watching of videos in class?}

At the beginning of the questionnaire, the students were asked about the extent and characteristics of their watching of videos between classes. About half watched most or all of the videos between classes; the others watched half or fewer in this manner. Thus, all respondents experienced a learning activity that is attributed to the implementation of the flipped-classroom approach.

The students were shown six items that tested their assessments of their watching of the videos and its contribution to the learning process (Cronbach's alpha $=.856$ ). Their responses (Table 1 ) show that watching the videos contributes to the learning process in respect of all statements examined: above all in amplifying interest, alleviating boredom, and enriching the learning activity and, to a smaller extent, in involvement in learning, understanding the learning material, and enhancing confidence in understanding it. 
Table 1: Students' attitudes toward watching videos between classes $(n=41)$

\begin{tabular}{|l|l|l|}
\hline Items & Mean & SD \\
\hline Makes the learning more interesting Every 3-4 days & 3.9 & 0.9 \\
\hline Alleviates boredom in study & 3.7 & 1.2 \\
\hline Enriches the learning activity & 3.7 & 0.7 \\
\hline Enhances my understanding of the learning material & 3.6 & 1.1 \\
\hline Enhances my involvement in the learning & 3.6 & 1.0 \\
\hline Enhances my confidence in understanding the learning material & 3.4 & 1.1 \\
\hline Overall average & 3.6 & 0.9 \\
\hline
\end{tabular}

*Using a five-point Likert scale ranged from 1 (not at all) to 5 (very much).

Watching videos between classes can take place anywhere that has an Internet connection and at any time of day or night. This flexibility is perceived as an advantage of an asynchronic learning. Another advantage of expanding the learning process to locations outside the classroom is the possibility that it will intensify the process. Despite the obvious advantages of watching videos between classes, however, the students in the course did not perceive these characteristics as advantageous. On the contrary! The questionnaire items that investigated students' preferences in watching videos, the extent of convenience in watching them between classes, and their viewing characteristics, show a clear preference for watching the course videos in class, in the presence of the lecturer and their classmates, and not between classes (Mean=3.9, SD=1.3), despite the acknowledged convenience of watching them between classes (Mean=3.5, $\mathrm{SD}=1.2$ ). Furthermore, the preferred place to watch the videos was divided almost equally between home $(43 \%)$ and at the college (41\%). Whereas most respondents $(63 \%)$ watched videos alone, a significant proportion $37 \%$ ) reported having watched them together with classmates. Thus, quite a few students preferred to limit their between-class learning to school premises (evidently, the library) and to do it together with their peers.

The responses to the open-ended item, in which the students were asked to explain their preferences in watching videos between classes or in class, reinforce the findings presented above-showing a clear preference for watching videos in class:

Watching [videos] in class is more efficient than between classes because the lecturer explains things that happen between the lines; between classes, we'd understand less and wouldn't know how things are related.

In class, you get additional explanation and focus on the videos; at home, you're on your own.

It's more convenient in class; participation and discussion among classmates helps to enrich the knowledge, unlike watching [the videos] between classes.

In class, things are discussed and explained. At home, you only see and you don't always get the message.

The lecturer's explanation and hearing the views of people in class helps you to understand what you hear in the video.

In class, there's a discussion about the video that helps you to understand the contents, gives you additional views about the topic, and helps you understanding the course.

The absence of a lecturer who guides and stewards the learning process is the main reason for the students' aversion to watching the videos away from class: 
It's more convenient for me to watch videos at home, where it's quiet, but in class it also contributes a great deal to me because the lecturer occasionally stops the video and explains and asks questions.

It should be noted that during the classroom sessions, the students watched a number of videos that were chosen by the instructor and were relevant to the course topics. This fact provides the desired anchor for comparison of watching videos between classes, as against watching videos in class.

\section{Research Question 2- What are the relations between the assessment of the contribution of the flipped-classroom approach to the learning process and the students' background characteristics, feelings about having the lecturer and classmates nearby, and self-assessment of the learning ability?}

To answer, a multivariate regression analysis was carried out. The dependent variable was an index of students' positions on the contribution to the learning process of watching videos between classes. The independent variables were:

- background characteristics-employment, gender, age;

- attitudes toward learning-sense of having lecturer and classmates nearby, selfassessment of learning ability.

Table 2: Multivariate regression for prediction of attitudes toward contribution of watching videos between classes $(n=41)$

\begin{tabular}{|l|l|l|l|}
\hline Variable & B & SE B & B \\
\hline Employment & -.52 & .16 & $-.52^{*}$ \\
\hline Gender & .53 & .30 & $.33^{* *}$ \\
\hline Age & .03 & .08 & $.07^{* *}$ \\
\hline Having classmates nearby & .19 & .13 & $.24^{* *}$ \\
\hline Having lecturer nearby & .09 & .12 & .11 \\
\hline Assessment of learning abilities & -.02 & .18 & -.01 \\
\hline R square & & .34 & \\
\hline Adjusted R square & & .21 & \\
\hline F & & $2.68^{*}$ & \\
\hline$*_{p<}^{*} 05^{*} p<1$ & & &
\end{tabular}

$* p<.05 * * p<.1$

As shown in Table 2, the independent variables explain, in the aggregate, $34 \%$ of the variance in students' attitudes toward the contribution to learning of watching videos between classes. The first significant explanatory variable in the multivariate analysis is employment: non-working students have a more favorable view on watching videos between classes than working ones (Means: 3.70 and 3.35; SDs: 0.27 and 0.15, respectively; Cohen's $d=1.63$ ). To explain this finding, one may note that working students (full-time or part-time) have less time for awayfrom-class study than non-working students.

The second variable in the analysis, although smaller in the effect size than the employment variable, is gender. Women (80\% of participants) are more favorably disposed to watching videos between classes than men (Means: 3.73 and 3.37; SDs: 0.68 and 0.93, respectively; Cohen's $\mathrm{d}=$ 0.44). This reinforces findings in other studies showing that women prefer a-synchronous online study because it allows them to balance family and scholastic commitments more easily (Müller, 2008). 
Next, a partial correlation between the assessment of watching videos between classes and the variable of employment, controlling for the gender variable, was calculated. The result shows that gender is a mediating variable that, when present, attenuates the bivariate correlation between employment and assessment of watching videos between classes $(r=-0.469, p<0.05)$. After the gender variable is controlled for, the partial correlation remains significant but weaker $(0.414$, $\mathrm{p}<0.05)$.

Age is the third background variable that explains the dependent variable. Its effect is positive, i.e., the older a student is, the more favorably he or she views the contribution of watching videos between classes. A possible explanation for this finding is that as people age they realize that the learning process is enriched and intensified when expanded beyond the classroom.

The sense of having classmates nearby also contributes positively to explaining the dependent variable; it is also the only significant variable in the multivariate analysis that investigates attitudes toward learning. Thus, the more a respondent values having classmates nearby, the more positively he or she assesses the contribution of watching videos between classes. This finding dovetails with previous studies that found that the stronger a student's sense of partnership with classmates in a learning community, the more favorably he or she assesses the learning process (Anderson, 2003; Moore \& Kearsley, 2005). To explain the result obtained, it is proposed that the students consider it possible to avail themselves of classmates if they have difficulty in understanding the video contents.

Notably, the sense of having the lecturer nearby and self-evaluation of learning ability did not contribute significantly to predicting the dependent variable. If so, the assessment of the contribution of using the flipped-classroom approach is not affected by personal feelings and assessments such as having the lecturer nearby and learning abilities.

\section{Conclusions and discussion}

The purpose of this study was to investigate, from the perspective of students, the implications of applying the flipped-classroom approach in an undergraduate course. A learning process such as the flipped classroom forces students to invest time in independent self-study away from class. In this research, they had to watch videos that included learning contents developed specifically for the course in order to prepare for the classroom activity.

Broadening the temporal and locational frame of study has both positive and negative implications: greater flexibility in study due to the choice of time and place for study (Moore \& Kearsley, 2005; Palloff \& Pratt, 2011; Subrahmanyam \& Šmahel 2011; Brookfield, 2013; Bonk \& Kahoo, 2014; Li et al., 2014; Selwyn, 2014) versus possible lack of confidence and frustration due to the absence of a guiding and helpful instructor in understanding the course contents (Lee \& Chan, 2001; Lim, 2002; Zhan \& Mei, 2013). Although the respondents appreciated the convenience of watching videos at the time and place of their choosing, most preferred to watch the videos at school and with their classmates-possibly to help each other and to marshal important peer support in the online learning process (Hirumi, 2006; Kurtz, 2014). Furthermore, it was found that the more important they felt it to have classmates nearby, the more strongly they believed that watching the videos made a contribution. Based on the literature, it might be that watching together promotes the sense of belonging to a learning community, and eventually contributing to the learning process (Anderson, 2003; Moore \& Kearsley, 2005; Li et al., 2014).

The students clearly preferred to watch the videos in class, together with the lecturer. The absence of a lecturer who guides and stewards the learning process was the main rationale for this preference. This finding is in-line with Griffin et al. (2009) who found that the synchronous mode is superior to the asynchronous mode in terms of pedagogical benefits. Another possible 
explanation for viewing in class is that it alleviates the burden of studies and makes less study time necessary. The multivariate analysis provided evidence for this by showing that non-working students were more favorably disposed than working students to the use of the flipped classroom manner. Additionally, however, it was found that women students had a more positive view of the technique than male students did. A possible reason for women's preference of an asynchronic online activity is that it gives them flexibility in balancing family and scholastic responsibilities (Müller, 2008). Finally, older students were more likely than younger ones to favour the flipped classroom approach. A possible explanation is that as people age they realize that the learning process is enriched and intensified when it is expanded beyond the classroom.

The findings support the assessment of the contribution of videos as a visual learning medium (Jukes, McCain \& Crockett, 2010; Levi-Atzmon, 2014). In the respondents' judgment, watching videos between classes abetted learning in the senses of amplifying interest, alleviating boredom, and enriching the learning process, and, to a lesser extent, as enhancing involvement in the learning, understanding of the learning material, and confidence in understanding it. A partial explanation of these findings is rooted in the lack of immediate ways to interact with the instructor, who may play a helping and guiding role in the learning process (Anderson, 2003).

To conclude, implementation of the flipped-classroom approach definitely poses a challenge to educators who are unaccustomed to away-from-class teaching or learning. The results of this study show that the mere assurance of temporal and locational flexibility in the study of visual scholastic contents, such as video films, may not attain its goal unless lecturer and classmates are available for interaction. Ways to provide learners with online help and support away from class, in real-time or time-delayed, should be examined. Proper implementation of the flippedclassroom approach may be helpful in developing an independent and active learner, one involved in the twenty-first century knowledge-based society.

\section{Limitation and future research}

This study has certain limitations that should be considered for further research. First, its small sample $(\mathbf{N}=41)$ limits its generalizability even to other courses. Readers may need to interpret the results carefully because this study is context-specific and involves a limited sample. It is clear that the authors do not intend to generalize these results to a wider population. However, the participants offered food for thought, providing both positive and negative attitudes toward the implementation of the flipped classroom approach as a legitimate learning method alongside the class meetings.

Despite the limited sample, the research data provides a different view point on the flipped classroom approach while implementing it with undergraduate students in an academic institution. It presents the need to explore and provide a better understanding of this approach that was examined so far mainly in k-12 settings or among students other than business students.

In future research, it is vital to extend this type of research to include representative groups of students who differ in their phase of study, individual characteristics, and learning content. Also, it would be helpful to study the effects of the flipped classroom approach on students' learning achievements and satisfaction. Moreover, it may be of interest to examine different types of course-videos (e.g., self-produced vs. off the shelf) and their impact on the learning process. Another possible direction is to examine these factors from a qualitative perspective to gain a more in-depth understanding on students' attitudes.

Finally, it is hoped that this research will provoke and encourage new thinking and new practices in the educational field with the use of the flipped classroom approach as a learning-teaching tool. 


\section{References}

1. Al-Seghayer, K. (2001). The effect of multimedia annotation modes on L2 vocabulary acquisition: A comparative study. In Language Learning \& Technology, 5(1), (pp. 202-232).

2. Anderson, T. (2003). Getting the mix right again: An updated and theoretical rationale for interaction. In International Review of Research in Open and Distance Learning, 4(2). Available online at http://www.irrodl.org/index.php/irrodl/article/view/149/230

3. Anderson, T. (2010). Theories for learning with emerging technologies. In G. Veletsianos (ed.), Immerging technologies in education, (pp. 23-36). Edmonton: AU Press.

4. Ang, R.P. (2005). Development and validation of the Teacher-Student Relationship Inventory using exploratory and confirmatory factor analysis. In The Journal of Experimental Education, 74(1), (pp. 55-73).

5. Baker, J.W. (2000). The "classroom flip": Using web course management tools to become the guide by the side. In Selected Papers from the 11th International Conference on College Teaching and Learning, (pp. 9-17).. Available online at http://works.bepress.com/j_wesley_baker/21/

6. Bonk, C.J. and Khoo, E. (2014). Adding some TEC-V ARIETY: 100+ Activities for motivating and retaining learners. Indiana: Open World Books.

7. Brookfield, S.D. (2013). Powerful techniques for teaching adults. San Francisco: John Wiley \& Sons.

8. Chen, C.M. and Wu, C.H. (2015). Effects of different video lecture types on sustained attention, emotion, cognitive load, and learning performance. In Computers and Education, 80, (pp. 108-121).

9. Fletcher, J.D. and Tobias, S. (2005). The multimedia principle. In R.E. Mayer (ed.), The Cambridge handbook of multimedia learning, (pp. 117-133).

10. Griffin, D.K.; Mitchell, D. and Thompson, S.J. (2009). Podcasting by synchronising PowerPoint and voice: what are the pedagogical benefits? In Computers and Education, 53(2), (pp. 532-539).

11. Harmon-Jones, E.; Simon, L.; Greenberg, J.; Pyszczynski, T.; Solomon, S.; McGregor, H. (1997). Terror management and self-esteem: Evidence that self-esteem reduces mortality salience effects. In Journal of Personality and Social Psychology, 72, (pp. 24-26).

12. Hirumi, A. (2006). Analyzing and designing e-learning interactions. In C. Juwah (ed.), Interactions in online education: Implications for theory and practice, (pp. 46-71). New York: Routledge.

13. Jukes, I.; McCain, T.; Crockett, L. (2010). Understanding the digital generation. Kelowna, B.C.: 21st Century Fluency Project \& Corwin.

14. Kurtz, G. ( ). Facebook Group as a space for interactive and collaborative learning. In The International Journal of Social Media and Interactive Learning Environments, 1(4), (pp. 406-418).

15. Kurtz, G. ( ). Integrating Facebook Group and a Course Website: The Effect on Participation and Perceptions on Learning. In American Journal of Distance Education, 28( ), (pp. 253-263).

16. Heatherton, T.F. and Polivy, J. (1991). Development and validation of a scale for measuring state self-esteem. In Journal of Personality and Social Psychology, 60, (pp. 895-910).

17. Lee, M.J.W. and Chan, A. (2007). Reducing the effects of isolation and promoting inclusivity for distance learners through podcasting. In Turkish Online Journal of Distance Education, 8(1), (pp. 85-105). 
18. Levi-Atzmon, G. (2014). Image-Supported Learning: Visual Language and Pedagogy. In N. Notzer (ed.), To Excel in Academic Teaching Lecturer Handbook of Updated Strategies and Competencies, (pp. 79-98). Or-Yehuda: The College for Academic Studies press (Hebrew)

19. Lewalter, D. (2003). Cognitive strategies for learning from static and dynamic visuals. In Learning and Instruction, 13(2), (pp. 177-189).

20. Li, F.; Qi, J.; Wang, G. and Wang, X. (2014). Traditional classroom vs. e-learning in higher education: Difference between students' behavioural engagement. In International Journal of Emerging Technologies in Learning, 9(2), (pp. 48-51).

21. Lim, D.H. (2002). Perceived differences between classroom and distance education: seeking instructional strategies for learning application. In International Journal of Educational Technology, 3(1), (pp. 21-35).

22. Lomicka, L. and Lord, C. (2007). Social presence in virtual communities of foreign language (FL) teachers. In System, 35(2), (pp. 208-228).

23. Mayer, R.E. (2005). Principles of Multimedia Learning Based on Social Cues: Personalization, Voice and Image Principles. In R.E. Mayer (ed.), The Cambridge handbook of multimedia learning, (pp. 201-212).

24. Meishar-Tal, H.; Kurtz, G. and Pitterse, E. (2012). Facebook groups as LMS: A case study. In The International Review of Research in Open and Distance Learning (IRRODL), 13(4), (pp. 33-48). Available online at http://www.irrodl.org/index.php/irrodl/article/view/1294/2337.

25. Means, B.; Toyama, Y.; Murphy, R.; Bakia, M.; Jones, K. (2010). Evaluation of evidence-based practices in online learning: A meta-analysis and review of online learning studies. Washington, DC: U.S. Department of Education, Office of Planning, Evaluation, and Policy Development. Available online at http://www2.ed.gov/rschstat/eval/tech/evidence-basedpractices/finalreport.pdf.

26. Moore, M.G. and Kearsley, G. (2005). Distance education: a systems view. Boston, MA: Wadsworth.

27. Morse, M. (2013). A quality of interrelating: describing a form of meaningful experience on a wilderness river journey. In Journal of Adventure Education and Outdoor Learning, 14(1), (pp. 42$55)$.

28. Müller, T. (2008). Persistence of women in online degree completion programs. In International Review of Research in Open and Distance Learning, 9(2). Available online at http://www.irrodl.org/index.php/irrodl/article/view/455/1042.

29. Noonoo, S. (2012). Flipped learning founders set the record straight. In THE Journal, Available online at http://thejournal.com/articles/2012/06/20/flipped-learning-founders-qand-a.aspx

30. Palloff, R.M. and Pratt, K. (2011). The excellent online instructor: Strategies for professional development. San Francisco, CA: Jossey-Bass.

31. Piersol, L. (2014). Listening Place. In Australian Journal of Outdoor Education, 17(2), (pp. 43-53).

32. Selwyn, N. (2014). The Internet and Education. In Chairman's Advisory, BBVA (eds.), 19 Key Essays on How Internet Changing our Lives, (pp. 191-217). OpenMind, BBVA. Available online at https://www.bbvaopenmind.com/en/article/the-internet-and-education/?fullscreen=true.

33. Subrahmanyam, K. and Šmahel, D. (2011). Digital Youth: The Role of Media in Development. Springer Science+Business Media, LLC., New York, NY. 
34. Zhan, Z. and Mei. H. (2013). Academic self-concept and social presence in face-to-face and online learning: Perceptions and effects on students' learning achievement and satisfaction across environments. In Computers \& Education, 6, (pp. 131-138). 